\title{
Arrested Development: Does the Grade Level at Which Juveniles Experience Arrest Matter?
}

\author{
Stephanie A. Wiley ${ }^{1}$
}

Received: 17 April 2015 /Revised: 4 October 2015 / Accepted: 9 November 2015 /

Published online: 16 November 2015

(C) Springer International Publishing AG 2015

\begin{abstract}
Purpose This study examines the effect of arrest on delinquency at a salient transition during adolescence: the move from middle to high school. The effects of arrest on delinquency via deviant attitudes, attenuation of prosocial bonds, and involvement with deviant groups are examined to determine whether labeling processes and consequences vary for youth in 7 th, 8 th, or 9 th grade.

Methods Longitudinal data from a school-based survey are used to estimate the direct and indirect effects of arrest on delinquency for youth in 7th, 8th, and 9th grades. Wald tests are used to determine whether there are significant differences across cohorts.

Results While arrest is associated with increased delinquency for all three grade cohorts, effects are most detrimental for 7 th graders. For these youth, arrest exerts a significant, direct effect across all intermediate outcomes and accounts for increased delinquency via neutralizations, weak school commitment, delinquent peers, and negative peer commitment. Although some of these mediators explain increases in delinquency among 8th and 9th graders, effects are smaller in magnitude. In total, arrest is associated with a $132 \%$ increase in delinquency among 7 th graders, but only a $55 \%$ increase among 9 th graders.

Conclusions The findings indicate that the effects of arrest become less severe as youth age and delinquency becomes "normative." It is recommended that the unintended consequences of arrest should be carefully considered-particularly for younger youth as they relate to deviant attitudes and commitment to and involvement with delinquent peers - and interventions should be coupled with efforts to improve prosocial attitudes and relations to prevent future delinquency. Although the effects of arrest wane over time, they do not disappear, and youth continue to experience consequences associated with arrest after they transition to high school.
\end{abstract}

Stephanie A. Wiley

wileysa@umsl.edu

1 Department of Criminology and Criminal Justice, University of Missouri-St. Louis, 324 Lucas Hall, 1 University Blvd., St. Louis, MO 63121, USA 
Keywords Arrest - Adolescence - Delinquency amplification · Labeling theory ·

Transition to high school

\section{Introduction}

Scholars have argued that the increasingly common experience of justice system involvement delays a number of salient transitions to adulthood, including high school completion, steady employment, and marriage [16, 42, 43, 54, 63, 72, 76]. In fact, a sizeable body of research indicates that both minor (e.g., being stopped and questioned by the police) and more serious (e.g., incarceration) forms of justice system contact are linked to consequences such as attenuation of prosocial bonds, involvement with deviant groups, and delinquent attitudes and behaviors [8, 9, 28, 47, 53, 77, 78]. Much less is known, however, about how the timing of justice system involvement during adolescence affects these outcomes.

The timing of justice system intervention during adolescence should be particularly important, as the number of physical and social changes, including puberty, school transitions, formation of new friendships, development of social identities, increasing autonomy, and more adult-like responsibilities, make this a turbulent time for many youth $[3,18]$. These stressors, when coupled with additional experiences such as family problems or trouble with the law, may be enough to derail normative developmental pathways into adulthood (for review, see [6]). Thus, the consequences of justice system involvement may be especially harmful when youth are navigating even normative transitions during adolescence.

One perspective that helps to clarify age-graded consequences of justice system involvement is labeling theory. Labeling theory asserts that contact with the justice system creates or reinforces deviant labels, which affects offending through three primary mechanisms: development of a deviant identity, social exclusion and prosocial bond attenuation, and involvement with delinquent peer groups [7, 45, 46, 60, 78]. Because "age-graded transitions...create both opportunities for crime and differential probabilities of detection and labeling by official agents of social control," researchers have called for examinations of labeling processes from a developmental framework to more fully understand how justice system interventions affect criminal and noncriminal outcomes ([63]:253). For example, reactions to and consequences of labels, including label internalization and access to deviant networks, likely differ depending on the age at which the labeling event occurs [45, 52].

The current study relies on longitudinal school-based data to examine whether there are differences in the effects of arrest among 7 th, 8th, and 9th graders by using path models to compare the effects of arrest on delinquency across these grade cohorts through three primary labeling pathways: development of deviant attitudes as a precursor to deviant identity, exclusion from prosocial activities and the attenuation of prosocial bonds, and greater involvement with delinquent peers. By focusing on this particular period of adolescence, this study examines the effects of arrest at a crucial time: the transition from middle to high school. This transition is often overlooked by researchers, which is curious given the numerous psychosocial and environmental changes that youth experience. Specifically, researchers have found that as youth settle into their first year of high school, they report decreased academic achievement, more 
negative views of the school environment, and lower self-esteem and are more delinquent than in previous years $[3,36,65]$. But while these changes may compound the consequences of arrest, the transition to high school also affords youth the increased anonymity of being in larger schools [66] and the chance to distance themselves from previous identities (see, for example, [41]), potentially including delinquent labels they have adopted as consequences of arrest.

As the avenues through which youth encounter the justice system increase (e.g., aggressive policing strategies, increased presence of officers in schools, early intervention programs) and the number of youth who experience justice system contact continues to grow (see $[39,61]$ ), it is important to understand how arrest amplifies delinquency and whether the age at which youth experience arrest serves to exacerbate or insulate juveniles from negative consequences. The results from this study inform both theory and policy by elaborating on the developmental components of labeling theory and providing age-specific recommendations for prevention and intervention efforts.

\section{The Labeling Process During Adolescence}

Adolescence is generally defined as the time from the onset of puberty to adulthood, roughly between the ages of 10 and 18 [67]. During pre- and early-adolescence (i.e., ages 10-13), youth become more attuned to others' judgments, increasingly reliant on social comparisons, and are especially vulnerable to adverse life events [17, 34, 44]. During this early adolescent period, delinquency and justice system contact are uncommon and are often viewed as important predictors of long-term offending (see [26, 50, 57]). By mid-adolescence (i.e., ages 14-17), however, youth are more secure in their self-concepts, self-esteem is on the rise, and peers serve as a primary source of norms and values as youth gain autonomy from their parents [17, 31, 58]. Moreover, delinquency becomes normative during these middle adolescent years, and because teenagers are generally stereotyped as "delinquent" or "rebellious" [14], their delinquent behavior is often dismissed [27, 57].

The developmental and social differences outlined here suggest that younger youth are particularly sensitive to labels applied by others and may be more likely to be labeled "delinquent" when they are arrested at age 11 or 12 because that type of behavior is not considered normal. Similar acts committed by older youth might elicit less serious reactions by adults and even peers because delinquent behavior is more common as youth approach the mid-to-late teens. Yet labeling theory and prior research do not explicitly outline age-graded variation in the labeling process during adolescence. In the following sections, three primary labeling mechanisms - deviant identity and attitudes, social exclusion and bond attenuation, and deviant group involvementalong with relevant research that highlights potential age variation in labeling processes, are discussed.

\section{Deviant Identity}

Initial formulations of labeling theory posited that delinquency amplification occurs primarily through the development of a deviant identity [45]. That is, youth who are 
officially identified as delinquents take on deviant identities as they fulfill expectations that are consistent with the deviant label. The adoption of a deviant identity occurs through reorganization of the labelee's orientations, values, attitudes, self-definitions, and behavior as the individual attempts to defend against or adjust to the problems created by societal reactions to the label ([45]: 76). Matsueda [55] posited that deviant identities are largely shaped by how individuals interpret the perceptions of reference groups. When youth feel that they are appraised or labeled by others as "rule violators," they are more likely to view themselves as delinquent and engage in delinquency.

There are two primary reasons to expect age differences regarding the effects of official labels on deviant identity. First, drawing from Matsueda's [55] work integrating labeling theory and symbolic interactionism, youth's reference groups fluctuate during pre-and early-adolescence (see also $[33,56]$ ). Younger adolescents are more likely to internalize deviant labels because reference groups consist of parents and other adults who view delinquency and justice system involvement as signs of early problem behavior. Alternatively, youth are more likely to rely on peers' beliefs and values as they approach mid-to-late adolescence $[29,58]$ and are more likely to view their own delinquent behavior as normative. Second, Lofland ([52]: 179) argued that individuals with weak orientations or "a less firm sense of...personal identity" are more likely to adopt deviant identities because they are more easily persuaded by labelers. Therefore, young individuals are more susceptible to deviant labels because they have fewer life experiences and limited knowledge of social positions and roles [52].

The small body of research that has examined differential effects of deviant labels during adolescence focuses on labels applied by parents and indicates that deviant labels are more detrimental for younger youth. Even when delinquent histories are similar, parents are more likely to label younger youth as delinquent when compared with older youth [33, 74, 81]. Using data from the National Youth Survey (NYS), Heimer and Matsueda [33] examined the relationship between deviant labels, identity, and delinquency among a sample of boys between the ages of 11 and 17 . Their findings indicated that parents were more likely to label younger boys, compared with their older counterparts, as "rule-violators" even after controlling for youth's prior selfreported delinquency. In another study that utilized data from the NYS, Triplett and Jarjoura [75] found that younger boys and girls were more likely to interpret parental labels as delinquent, regardless of parents' objective labels. Although this research is limited to parental labeling, these findings support the notion that societal expectations and reactions to delinquency, as well as youth's perceptions of labels, vary throughout adolescence, with youth being particularly susceptible to delinquent labels in late childhood and early adolescence.

\section{Social Exclusion and Bond Attenuation}

Once the individual has been labeled, society often creates barriers to limit participation in conventional activities, groups, and opportunities. The stigma associated with justice system involvement should trigger social exclusion and barriers to conventional opportunities because the deviant label becomes a master status, whereby labeled individuals are seen primarily as delinquent or criminal [5]. Theoretical elaborations of the exclusionary process highlight diminished social ties as a consequence of labels; society may reject the labelee or the labelee withdraws from conventional groups and 
opportunities $[48,49,63,64]$. Yet the degree of social exclusion or withdrawal should depend, in part, on the labelee's age and societal acceptance of the behavior. As Moffitt [57] notes, youth who participate in delinquency and antisocial behaviors at an early age (i.e., life-course persistent youth) are seen as "troublemakers" and are excluded by their prosocial peers, but as these youth grow older, their same-age peers begin to mimic, rather than reject, their deviant behavior because it signals independence and adulthood. Thus, justice system involvement during the later teenage years should be less stigmatizing than involvement that occurs earlier because it is less likely to elicit social exclusion and might even be admired.

Earlier labeling may also be linked to more detrimental outcomes throughout life because of the cumulative effect that labels have on later relationships and opportunities. In their theory of cumulative disadvantage, Sampson and Laub ([64]: 147-150) propose that justice system involvement during adolescence leads to strained relationships, fewer educational opportunities, and poorer job and marriage prospects in adulthood. When labels are applied earlier in life, such as during early adolescence, they have more time to accumulate additional consequences that block opportunities throughout adolescence, which then lead to decreased conventional opportunities in adulthood. In one of the few studies to assess the consequences of official labels at different ages during adolescence, De Li [16] examined the effects of court convictions on unemployment, status achievement (i.e., whether youth had taken General Certificate of Education exams, job status, and job stability), and later delinquency among a sample of London-born working class boys. The researcher found that convictions at younger ages (i.e., 10-13) were associated with a greater likelihood of unemployment, which was in turn associated with increased delinquency between the ages of 14 and 15 . Youth convicted between the ages of 14 and 16 were also more delinquent later on, but the magnitude of this relationship was smaller. Although this study did not explicitly test for age differences, it provides initial support for the notion that the consequences of justice system involvement unfold throughout adolescence and these consequences are most harmful for younger youth.

\section{Involvement with Delinquent Groups}

The final mechanism through which official labels are believed to lead to increased delinquency is involvement with deviant groups. Labeled individuals often seek acceptance from and involvement with deviant groups because they are excluded by prosocial others or are drawn to those with similar experiences and attitudes $[30,45,52$, 60]. Delinquent groups also serve to enhance or reinforce deviant identities because they provide norms, definitions, and behaviors favorable to delinquency [56]. Some theorists note that labeled individuals must join deviant groups if they wish to experience group solidarity and fully accept the deviant label, but not all individuals are exposed to deviant groups or are seen as desirable deviant group members [5, 45, 52]. Because exposure to and acceptance of deviant peer groups increase as youth age [19, 57], younger youth should have limited access to delinquent groups compared with their older peers.

Prior research has highlighted the central role of deviant group involvement in the labeling process $[9,40,78]$ but few studies have examined how the relationship between justice system involvement and delinquent groups varies during adolescence. 
In one of the few studies to examine the age-graded effects of justice system involvement on deviant group involvement, Johnson et al. [38] used longitudinal data from the Iowa Youth and Families Project to assess the relationship between justice system involvement (e.g., arrest, juvenile detention/jail, probation), deviant peers, and delinquency among a sample of 153 boys who were followed from 7 th grade to 3 years posthigh school. Their results indicated that the effect of justice system involvement on deviant peer associations was stronger during mid-adolescence (i.e., system involvement during 8th/9th grade and deviant peers at 10th grade) than at older ages (i.e., system involvement in 12th grade and deviant peers 3 years later). Although this study focuses on mid-to-late adolescence, it provides support for the idea that the relationship between justice system contact and delinquent group involvement is strongest during the peak of delinquency and, perhaps, when deviant groups are more readily available. If younger adolescents have limited access to deviant groups than youth in their midteens, they should be less likely to become involved with delinquent peers and therefore less vulnerable to the negative consequences of arrest as they relate to involvement with deviant groups.

\section{The Current Study}

To summarize, official labels are believed to increase delinquency simultaneously through three primary mechanisms: development of a deviant identity, social exclusion and the attenuation of prosocial bonds, and involvement with delinquent groups. Although theory and prior research indicate that there are age-graded differences in these processes, few studies have explicitly examined whether they vary during adolescence. Several of the studies reviewed here indicate that pre-teens, as compared with their older counterparts, are more susceptible to adoption of deviant identity and attenuation of prosocial bonds as a result of unofficial (e.g., parental) or official (e.g., court conviction) labeling. Additionally, prior research suggests that there are age differences in terms of access to conventional activities and peer groups, but because these studies relied on unique samples of youth - De Li's [16] study examined a sample of boys born in London in 1953 while Johnson et al. [38] used a sample of rural residents - it is unknown whether similar findings will emerge with more representative samples. Importantly, prior studies are also limited in that they assess only single labeling mechanisms rather than the three primary pathways and the overall agevarying consequences of arrest are unknown. If, for example, the effects of arrest on deviant identity are more detrimental for younger youth, but the consequences of arrest on delinquent peer associations are worse for older youth, then the overall effects on later delinquency will be similar while the mechanisms that account for increased delinquency vary.

The current study aims to fill gaps in the labeling literature by assessing the differential effect that arrest has on the three primary labeling mechanisms associated with increased delinquency. Although prior research indicates that arrest, as well as less severe forms of justice system contact such as being stopped and questioned, have similar detrimental effects $[13,77,78]$, the focus of this study is on arrest because this experience is more likely to draw attention from others and elicit stronger exclusionary reactions than simply being stopped. Longitudinal data provide a 3-year window for 
each of the groups, such that control variables are measured in the 6th, 7th, or 8th grade; arrest and mediators are measured in 7th, 8th, or 9th grade; and delinquency is measured in 8th, 9th, or 10th grade for the respective cohorts, with same-grade counterparts serving as comparison groups. Although these grade cohorts capture relatively small age differences, they allow for close examination of variation in the labeling process at an underexplored point during adolescence: the transition from middle to high school. This context may have important implications, as the younger cohort remained in middle school throughout the study period-likely with many of the same peers and teachers - while the remaining cohorts experienced changes in surroundings and peers at varying time points, which could potentially offer these arrested youth a chance to break away from former labels (see, for example, [41]). However, because the transition to high school is often accompanied by a number of psychosocial changes $[3,6]$, a concurrent experience with the justice system could further complicate a transition that is already rocky for many youth.

Drawing from labeling theory and prior research, three hypotheses form the basis for this study regarding the effects of arrest through primary labeling mechanisms:

Hypothesis 1: Compared with their older counterparts, younger youth are less secure in their identities and are more likely to adopt deviant attitudes after experiencing arrest.

Hypothesis 2: Because delinquency is not yet considered normative during early adolescence, younger youth who experience arrest are more likely to be excluded from prosocial groups and activities and should have weaker prosocial ties and opportunities than their older counterparts.

Hypothesis 3: Compared with their older peers, younger youth have less access to deviant peer groups and should be less likely to increase involvement with delinquent groups following arrest.

The three hypotheses that form the basis for this study are concerned with the indirect effects of arrest on the labeling mechanisms because these are the primary pathways specified by labeling theory and its elaborations. Specific hypotheses regarding the direct effect of arrest on delinquency, as well as the direct effects of the labeling mechanisms on delinquency, are outside of the scope of this paper; however, results for all cohorts are presented and compared and meaningful group differences in direct and indirect paths are discussed. Because it is unknown what effect, if any, the transition to high school will have on the labeling process, hypotheses related to high school transitions are excluded, but potential influences are included in the discussion.

\section{Data and Methods}

\section{Data}

The data for this study come from a sample of youth involved in the second National Evaluation of the Gang Resistance Education and Training (G.R.E.A.T.) program (for more information, see $[23,24]$ ). The G.R.E.A.T. program is taught by police officers in middle schools and is aimed at preventing youth violence and gang membership. 
Across the seven geographically and ethnically diverse cities (Albuquerque, NM; Chicago, IL; Dallas/Fort Worth area, TX; Greeley, CO; Nashville, TN; Philadelphia, PA; and Portland, OR) selected for the evaluation, 31 middle schools participated in the program. Classrooms were randomly assigned to receive the G.R.E.A.T. program or to serve as controls. Active parental consent was received for $3820(77.9 \%)$ of the eligible youth [22].

Five of the six waves of G.R.E.A.T. data were pooled for the current study to take advantage of the various grade levels at which youth experienced arrest such that control variables are measured at time 1 (T1) (waves 1, 3, and 4), arrest and mediators at time 2 (T2) (waves 3, 4, and 5), and delinquency at time 3 (T3) (waves 4, 5, and 6) with a 1-year lag between each time point. ${ }^{1}$ Although arrest and mediators are measured at T2, proper temporal ordering is maintained because arrest is based on youth's reported arrest during the past 6 months and the mediators are primarily concerned with current attitudes and activities. Pooling observations resulted in a dataset with 10,839 observations nested within 3818 individuals. ${ }^{2}$ Because individuals who experienced arrest were not necessarily included in each of the cohort analyses (see "Arrest" section), a total of 8343 observations nested within 3818 individuals contribute to the final analysis.

Descriptive information is presented separately for each cohort in Table 1 . There is approximately a 1-year age difference between each of the three cohorts, with youth in the 7th grade cohort 12.41 years old at the time of arrest, youth in the 8th grade cohort 13.37, and those in the 9th grade cohort 14.35, on average. The cohorts are almost evenly split between females and males and are predominately white or Hispanic, followed by black and "other" race or ethnicity. Youth in the 7th grade cohort are slightly less likely to be Hispanic and are less likely to come from Albuquerque or Chicago. ${ }^{3}$ Consistent with the age-crime curve, delinquency at both T1 and T3 are higher for the 8th and 9th grade cohorts. The percentage of youth who were arrested in the 8 th grade is slightly higher than in the 7 th or 9 th grade.

\section{Measures}

\section{Delinquency}

The dependent variable, delinquency, is measured at T3. Youth were asked how many times in the last 6 months they had participated in 14 different delinquent activities ranging in seriousness from "skipped classes without an excuse" to "attacked someone with a weapon." The 11 response categories capture the number of times youth participated in each activity, from " 0 " to "more than 10." Responses for each item were summed to create a delinquency frequency measure ranging from 0 to 154 . Due to the skewed nature of the delinquency measure, delinquency frequency was transformed

\footnotetext{
${ }^{1}$ Wave 2 from the G.R.E.A.T. data is not used because it was collected 3 to 4 months after wave 1 and 6 to 8 months prior to wave 2 . Inclusion of this wave would have created inconsistent timing windows among the three cohorts.

${ }^{2}$ Although the full sample of youth is 3820 , two cases were removed from analyses due to inconsistent and problematic survey responses.

${ }^{3}$ This difference is due to the fact that youth in five schools in Albuquerque and Chicago, two study sites with larger proportions of Hispanic youth, were in 7 th grade at the start of the G.R.E.A.T. evaluation.
} 
Table 1 Descriptive characteristics

\begin{tabular}{|c|c|c|c|c|c|c|c|c|c|}
\hline & \multicolumn{3}{|c|}{7 th grade $(n=2764)$} & \multicolumn{3}{|c|}{8 th grade $(n=3046)$} & \multicolumn{3}{|c|}{ 9th grade $(n=2533)$} \\
\hline & $\begin{array}{l}\text { Percent/ } \\
\text { Mean }\end{array}$ & SD & Range & $\begin{array}{l}\text { Percent/ } \\
\text { Mean }\end{array}$ & SD & Range & $\begin{array}{l}\text { Percent/ } \\
\text { Mean }\end{array}$ & SD & Range \\
\hline \multicolumn{10}{|c|}{ Time-invariant demographic characteristics: } \\
\hline Age & 12.41 & .59 & $11-16$ & 13.37 & .56 & $11-17$ & 14.35 & .56 & $13-17$ \\
\hline \multicolumn{10}{|l|}{ Sex } \\
\hline \multicolumn{10}{|l|}{ Female } \\
\hline Male & $49.6 \%$ & & & $47.8 \%$ & & & $47.3 \%$ & & \\
\hline \multicolumn{10}{|l|}{ Race/ethnicity } \\
\hline White & $30.8 \%$ & & & $28.0 \%$ & & & $29.2 \%$ & & \\
\hline Black & $19.9 \%$ & & & $16.4 \%$ & & & $15.8 \%$ & & \\
\hline Hispanic & $34.8 \%$ & & & $41.1 \%$ & & & $40.3 \%$ & & \\
\hline Other & $14.5 \%$ & & & $14.5 \%$ & & & $14.7 \%$ & & \\
\hline \multicolumn{10}{|l|}{ City } \\
\hline Albuquerque & $7.8 \%$ & & & $16.1 \%$ & & & $13.0 \%$ & & \\
\hline Chicago & $7.3 \%$ & & & $14.1 \%$ & & & $12.1 \%$ & & \\
\hline Dallas/Ft. Worth suburb & $19.5 \%$ & & & $15.5 \%$ & & & $16.8 \%$ & & \\
\hline Greeley & $17.8 \%$ & & & $14.3 \%$ & & & $15.1 \%$ & & \\
\hline Nashville & $18.5 \%$ & & & $15.6 \%$ & & & $17.1 \%$ & & \\
\hline Philadelphia & $13.3 \%$ & & & $10.9 \%$ & & & $10.8 \%$ & & \\
\hline Portland & $15.9 \%$ & & & $13.5 \%$ & & & $15.1 \%$ & & \\
\hline \multicolumn{10}{|l|}{ Highest parent education } \\
\hline Less than high school diploma & $11.2 \%$ & & & $12.2 \%$ & & & $11.7 \%$ & & \\
\hline High school diploma & $42.1 \%$ & & & $43.9 \%$ & & & $43.5 \%$ & & \\
\hline College degree & $46.8 \%$ & & & $43.9 \%$ & & & $44.8 \%$ & & \\
\hline Participated in G.R.E.A.T. & $52.4 \%$ & & & $54.0 \%$ & & & $54.6 \%$ & & \\
\hline \multicolumn{10}{|l|}{ T1 control variables: } \\
\hline Single-parent household & $20.1 \%$ & & & $20.3 \%$ & & & $22.3 \%$ & & \\
\hline Low self-control & 2.75 & .66 & $1-5$ & 2.72 & .71 & $1-5$ & 2.66 & .68 & $1-5$ \\
\hline Conflict resolution skills & 2.20 & .45 & $1-3$ & 2.14 & .45 & $1-3$ & 2.16 & .43 & $1-3$ \\
\hline Positive peer commitment & 4.25 & 1.14 & $1-5$ & 4.16 & 1.12 & $1-5$ & 4.10 & 1.10 & $1-5$ \\
\hline School/comm. disorder & 1.83 & .57 & $1-3$ & 1.74 & .52 & $1-3$ & 1.62 & .49 & $1-3$ \\
\hline Victimization (logged) & 1.62 & 1.27 & $0-4.55$ & 1.66 & 1.26 & $0-4.80$ & 1.49 & 1.24 & $0-4.56$ \\
\hline Substance use (logged) & .09 & .30 & $0-2.56$ & .18 & .43 & $0-2.83$ & .26 & .52 & $0-2.83$ \\
\hline Lack of guilt & 1.30 & .53 & $1-3$ & 1.41 & .57 & $1-3$ & 1.52 & .59 & $1-3$ \\
\hline Neutralizations & 2.43 & .74 & $1-5$ & 2.68 & .81 & $1-5$ & 2.73 & .81 & $1-5$ \\
\hline Poor grades & 1.97 & .76 & $1-5$ & 2.20 & .87 & $1-5$ & 2.17 & .82 & $1-5$ \\
\hline Weak school commitment & 2.02 & .66 & $1-4.86$ & 2.27 & .74 & $1-5$ & 2.31 & .72 & $1-5$ \\
\hline Prosocial activity exclusion & 1.54 & 1.12 & $0-4$ & 1.74 & 1.19 & $0-4$ & 1.81 & 1.25 & $0-4$ \\
\hline Prosocial peer exclusion & 2.48 & .95 & $1-5$ & 2.61 & .98 & $1-5$ & 2.55 & .94 & $1-5$ \\
\hline Delinquent peers & 1.23 & .44 & $1-5$ & 1.35 & .57 & $1-5$ & 1.40 & .55 & $1-5$ \\
\hline Negative peer commitment & 1.61 & .80 & $1-5$ & 1.84 & .93 & $1-5$ & 1.97 & .99 & $1-5$ \\
\hline Delinquency frequency & 3.59 & 9.02 & $0-140$ & 5.05 & 11.22 & $0-154$ & 5.10 & 10.33 & $0-121$ \\
\hline Delinquency (logged) & .76 & 1.05 & $0-4.95$ & 1.00 & 1.13 & $0-5.04$ & 1.03 & 1.14 & $0-4.80$ \\
\hline \multicolumn{10}{|l|}{$\mathrm{T} 2$ variables: } \\
\hline Moved this year & $23.5 \%$ & & & $18.8 \%$ & & & $19.8 \%$ & & \\
\hline
\end{tabular}


Table 1 (continued)

\begin{tabular}{|c|c|c|c|c|c|c|c|c|c|}
\hline & \multicolumn{3}{|c|}{7 th grade $(n=2764)$} & \multicolumn{3}{|c|}{8 th grade $(n=3046)$} & \multicolumn{3}{|c|}{ 9th grade $(n=2533)$} \\
\hline & $\begin{array}{l}\text { Percent/ } \\
\text { Mean }\end{array}$ & SD & Range & $\begin{array}{l}\text { Percent/ } \\
\text { Mean }\end{array}$ & SD & Range & $\begin{array}{l}\text { Percent/ } \\
\text { Mean }\end{array}$ & SD & Range \\
\hline Arrested & $6.2 \%$ & & & $7.0 \%$ & & & $5.2 \%$ & & \\
\hline Lack of guilt & 1.44 & .60 & $1-3$ & 1.57 & .61 & $1-3$ & 1.60 & .60 & $1-3$ \\
\hline Neutralizations & 2.69 & .84 & $1-5$ & 2.80 & .83 & $1-5$ & 2.71 & .79 & $1-5$ \\
\hline Poor grades & 2.18 & .89 & $1-5$ & 2.24 & .85 & $1-5$ & 2.22 & .85 & $1-5$ \\
\hline Weak school commitment & 2.29 & .76 & $1-5$ & 2.36 & .75 & $1-5$ & 2.28 & .69 & $1-5$ \\
\hline Prosocial activity exclusion & 1.72 & 1.20 & $0-4$ & 1.83 & 1.25 & $0-4$ & 1.85 & 1.26 & $0-4$ \\
\hline Prosocial peer exclusion & 2.60 & .99 & $1-5$ & 2.62 & .96 & $1-5$ & 2.42 & .86 & $1-5$ \\
\hline Delinquent peers & 1.38 & .62 & $1-5$ & 1.48 & .65 & $1-5$ & 1.54 & .64 & $1-4.71$ \\
\hline Negative peer commitment & 1.86 & .98 & $1-5$ & 2.02 & 1.03 & $1-5$ & 1.99 & .99 & $1-5$ \\
\hline \multicolumn{10}{|l|}{ T3 variables: } \\
\hline Moved this year & $17.5 \%$ & & & $19.1 \%$ & & & $17.2 \%$ & & \\
\hline Delinquency frequency & 7.28 & 16.82 & $0-154$ & 6.88 & 14.98 & $0-154$ & 6.81 & 14.89 & $0-154$ \\
\hline Delinquency (logged) & 1.16 & 1.26 & $0-5.04$ & 1.16 & 1.24 & $0-5.04$ & 1.19 & 1.21 & $0-5.04$ \\
\hline
\end{tabular}

Mean and standard deviation listed for continuous variables; percent listed for dichotomous variables. Ranges presented for continuous variables only

$S D$ standard deviation

by adding 1 and taking the natural log. Examining a log-transformed variable with traditional regression methods may bias results (see [59]), but because the interpretation of indirect effects relies on linear relationships [32], the log-transformed version of delinquency was selected as the most appropriate form of the outcome for the current study. ${ }^{4}$

\section{Arrest}

A dichotomous measure of arrest at T2 is the independent variable in this study. Respondents were asked how many times in the past 6 months they had been arrested. If youth indicated that they were arrested at least once during the prior 6 months, they were coded as "1. Arrested." Youth who were arrested multiple times are excluded from analyses at subsequent grades to avoid confounding the effect of multiple arrests because the effect of arrest may differ as arrests accumulate over the life course. For example, a student arrested in 7th grade is included in the arrested group in the 7th grade analysis, but is excluded from the 8th and 9th grade analyses. Students who were never arrested contribute to the final analysis for all three grade cohorts.

\footnotetext{
${ }^{4}$ Several steps were taken to ensure that results are robust to alternative outcome specifications. First, a variety score outcome (sum of dichotomous yes/no responses to each of the 14 delinquent items) was included in a negative binomial regression analysis (controlling for all $\mathrm{T} 1$ and $\mathrm{T} 2$ variables included in the path model) to determine whether the direct effects on delinquency hold. Second, path models were examined using a logtransformed measure of street delinquency (see [21]), which includes eight of the more serious, street-level acts to determine whether less serious delinquency drives the results presented in this paper. Results of both supplementary analyses are substantively similar and results are available upon request.
} 


\section{Deviant Attitudes}

Two measures of deviant attitudes are included in this study to capture youth's attitudes as they begin to adopt deviant identities (see [1]). The first, lack of guilt, relies on respondents' anticipated guilt if they were to participate in delinquent activities ranging from "stealing something worth less than \$50" to "attacking someone with a weapon." Responses for the seven-item scale are reverse-coded such that higher scores are consistent with less guilt: "1. Very guilty," "2. Somewhat guilty," and "3. Not very guilty" $(\alpha=.93)$. The second measure of delinquent attitudes, agreement with neutralization statements, comes from a nine-item scale capturing how much respondents agree with statements such as, "It's okay to tell a small lie if it doesn't hurt anyone," "It's okay to steal something if that's the only way you could ever get it," and "It's okay to beat someone up if they hit you first." Response choices are based on a five-point Likert scale ranging from "1. Strongly disagree" to "5. Strongly agree" $(\alpha=.84)$.

\section{Attenuated Bonds and Prosocial Exclusion}

To assess the strength of youth's bonds to conventional society, two variables are included. The first is a measure of poor grades to help capture students' academic achievement. Students indicated whether their current grades were closest to A's, B's, C's, D's, or F's, and corresponding numerical values are reverse-coded so that higher scores represent worse grades. Weak school commitment is a seven-item scale $(\alpha=.78)$. Youth were asked to indicate how much they agree or disagree with statements such as, "I try hard in school" and "Grades are very important to me." Response categories are reverse-coded to range from "1. Strongly agree" to "5. Strongly disagree."

Two variables capture exclusion from conventional activities and peers. Youth were asked to respond "yes" or "no" to whether they participated in any school activities or athletics, community activities, religious activities, or their own family activities in the past year. A variety score was computed and is based on respondents' answers for each activity, which is reverse-coded to represent prosocial activity exclusion. A score of " 0 " indicates that the respondent was not excluded from any of the prosocial activities and a score of "4" indicates that the respondent was excluded from all four types of activities. The prosocial peer exclusion measure consists of a four-item scale $(\alpha=.84)$. Youth were asked how many of their current friends, for instance, "have been thought of as good students," or "have generally been honest and told the truth." Response categories are reverse-scored such that " 1 . All of them" and "5. None of them."

\section{Deviant Group Involvement}

The delinquent peers scale consists of seven questions asking youth, for example, how many of their current friends "skipped school without an excuse," "attacked someone with a weapon," or "used marijuana or other illegal drugs" $(\alpha=.86)$. Responses range from " 1 . None of them" to "5. All of them." To account for the possibility that youth also become more committed to their delinquent friends, a three-item scale of deviant peer commitment is included. This variable captures the likelihood that youth would continue to hang out with their delinquent friends if those friends were getting them into trouble: (1) at school, (2) at home, and (3) 
with the police. Responses are scored on a five-point Likert-type scale ranging from "1. Not at all likely" to "5. Very likely" $(\alpha=.81)$.

\section{Control Variables}

To help ensure that the results of this study are not influenced by pre-existing characteristics associated with arrest or delinquency, a number of variables are included as controls. ${ }^{5}$ Time-stable control variables include sex (with males coded as 1 ), race (indicators for Hispanic, black, and other race with white youth serving as the reference category), city of residence (dichotomous indicators for six of the seven cities, with the Dallas/Ft. Worth area suburb as the reference group), highest parent education (dichotomous indicators for less than high school and college degree, with high school completion as the reference group), and an indicator of whether the youth participated in the G.R.E.A.T. program. Time 1 control variables include single-parent household, low self-control, conflict resolution skills, commitment to positive peers, perceived disorder in the school and community, victimization (logged), substance use (logged), and prior levels of the mediators and outcome (i.e., T1 values for lack of guilt, neutralizations, poor grades, weak school commitment, prosocial activity exclusion, prosocial peer exclusion, peer delinquency, deviant peer commitment, and delinquency). In addition to these control variables, equation-specific indicators for whether youth had a change of residence between T1 and T2 or T2 and T3 were included. ${ }^{6}$

\section{Analysis}

The primary purpose of this study is to determine whether the effects of arrest on subsequent labeling processes and delinquency vary by grade level or social age. This study relies on path analysis with maximum likelihood for missing values (MLMV) in Stata 13 [69]. This method addresses problems with missing or incomplete data by allowing all cases to be used in the analysis even if they have missing data on one or more variables (see [2]). Models for each grade are estimated simultaneously while allowing intercepts, structural coefficients, and covariances to vary across groups. Clustered standard errors are employed to account for inclusion of repeated observations across the three groups. Wald tests are used to determine whether differences in path coefficients are significantly different from zero and $z$ scores are adjusted to account for interdependence of observations ([79]; for an applied example, see [73]). ${ }^{7}$

Path models that allow for multiple mediation are preferred to single mediation models because each indirect effect is conditional on other indirect effects in the model

\footnotetext{
${ }^{5}$ The issue of selection bias is a common concern when assessing the effects of justice system involvement (for discussion, see [68]). Robustness against selection bias was assessed by estimating the direct effects of arrest on the mediators and delinquency using propensity score matching techniques (e.g., [47], [77]). The patterns are consistent with the results presented here and results are available upon request.

${ }^{6}$ For equations involving the mediators as outcomes, the indicator for moving between $\mathrm{T} 1$ and $\mathrm{T} 2$ was included; the indicator for moving between $\mathrm{T} 2$ and $\mathrm{T} 3$ was included in equations in which delinquency was the outcome.

${ }^{7}$ The following equation is used to adjust for the fact that the coefficient covariances across groups are not equal to zero: $z=\frac{b_{1}-b_{2}}{\sqrt{\left(s e 1^{2}+s e 2^{2}-2\left[\operatorname{cov} b_{1}, b_{2}\right]\right)}}$
} 
and error terms for each of the mediators are allowed to covary to account for shared sources of error [62]. This allows for a more theoretically relevant analysis, as the indirect effect of arrest through delinquent peers, for instance, is influenced by the inclusion of the indirect effect through prosocial peer exclusion. Labeling theory and its extensions indicate that the direct effect of justice system involvement on delinquency should disappear once the mechanisms that account for increased delinquency are taken into account (e.g., see [7, 60]); yet prior research has shown that a direct effect between justice system contact and delinquency remains even after accounting for indirect effects $[40,78]$. Therefore, a direct effect between arrest and delinquency is included to capture any effects not accounted for by the mediators.

The six primary sets of paths estimated and compared across the groups include: (1) the direct effect of arrest on each of the mediators (a paths), (2) the direct effects of the mediators on delinquency (b paths), (3) the direct effect of arrest on delinquency (c' path), (4) the specific indirect effects of arrest on delinquency through each mediator (ab paths), (5) the total indirect effect of arrest on delinquency through all mediators simultaneously (sum of ab paths), and (6) the total effect of arrest on delinquency (c path; i.e., the sum of ab and c' paths). The complete model is depicted in Fig. 1.

\section{Results}

Path analysis results for the three grade cohorts are presented in Table 2. When reviewing these results, it is important to consider the 1-year lag between T2 and T3. For example, youth in the younger cohort were in 7 th grade when arrest occurred (T2) and when the mediators were measured, but were in 8th grade when delinquency was measured (T3). All path coefficients are unstandardized and both coefficients and cohort differences are significant at $p<.05$ unless otherwise noted.

The first set of results (a paths) indicate that the direct effects of arrest on labeling mechanisms are largely consistent with labeling theory for all cohorts, although the effects are widest-ranging and strongest in magnitude among the 7th grade cohort. Across all grades, arrest is associated with less guilt, greater agreement with neutralization statements, less commitment to school, more exclusion from prosocial peers, and greater involvement with delinquent peers. Among 8th graders, arrest is linked to additional detrimental outcomes: worse grades and greater commitment to negative peers. Meanwhile, arrest in 7 th grade affects all of the intermediate outcomes. With the exception of differences in the effects of arrest on poor grades, all of these effects are significantly stronger among 7 th graders compared with 8 th and/or 9th graders. For example, arrest is associated with a .42-unit increase in weak school commitment among 7th graders, which is significantly greater than the .22-unit increase among 8th graders and the .13-unit increase within the 9th grade cohort. Meanwhile, there are no significant differences in the effects of arrest for 8th versus 9th graders. That is, the direct effects of arrest on labeling mechanisms are essentially identical for 8th and 9th graders.

Interpretations of the direct effects of the labeling mechanisms on delinquency (b paths) reflect the log-transformed delinquency outcome, and exponentiated 


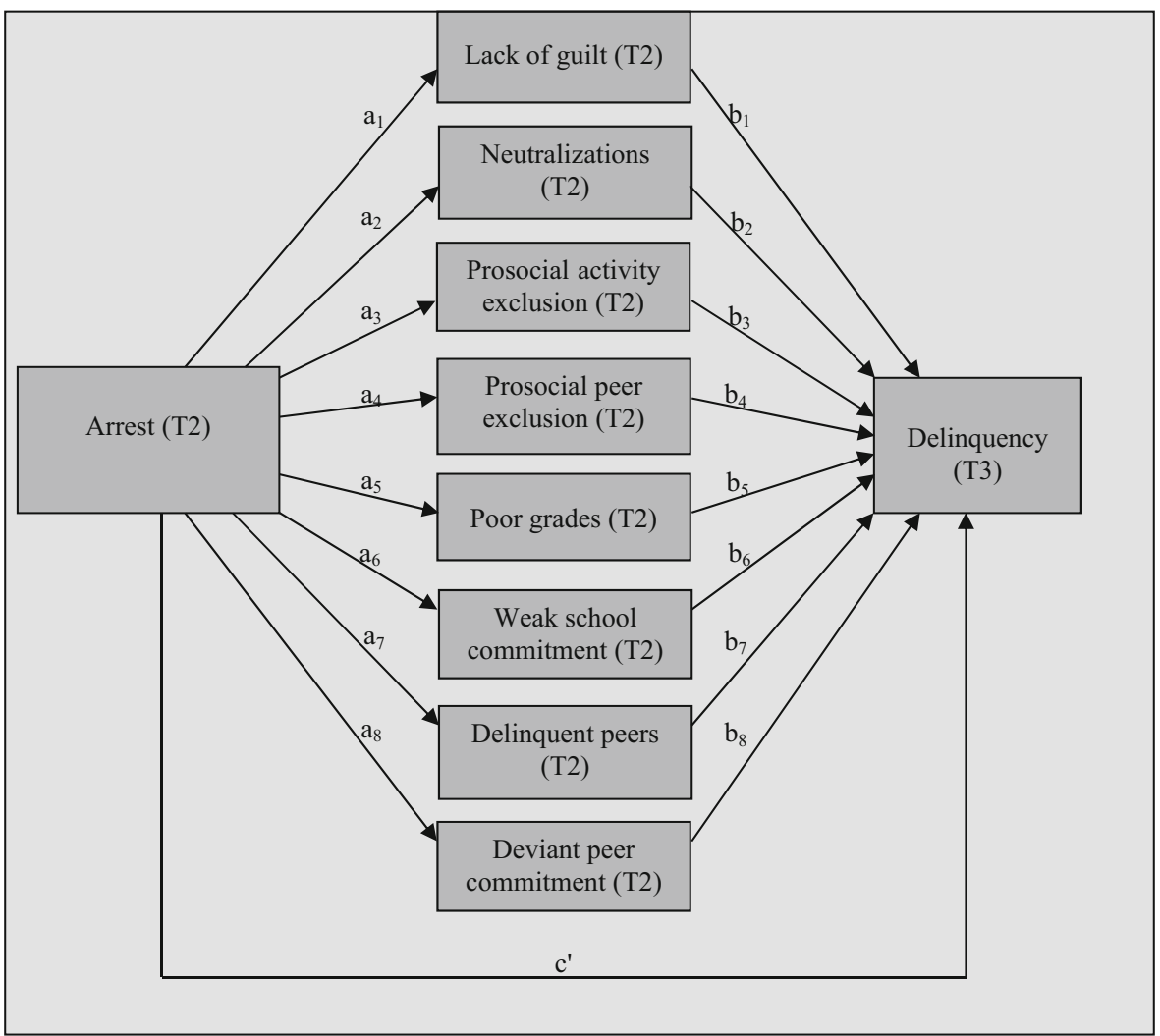

Fig. 1 Path model. To reduce the number of paths presented in the model, control variables and error covariances are omitted

coefficients are included in the table and interpreted as a percentage change in delinquency. ${ }^{8}$ For example, a 1-unit increase in agreement with neutralization statements is associated with a $25 \%$ increase for 7 th graders, a $24 \%$ increase for 8 th graders, and a $19 \%$ increase for 9 th graders. Across all three groups, neutralizations, weak school commitment, and delinquent peers are linked to increased delinquency. Meanwhile, lack of guilt and poor grades are also associated with increased delinquency for the 8th and 9th grade cohorts and negative peer commitment is linked to increased delinquency for 7 th graders only. Here, there are few differences across grade level. Wald tests indicate that the effect of lack of guilt on delinquency among 8th graders is significantly larger than the effect among 7th graders. Moreover, negative peer commitment is associated with a greater increase in delinquency among 7th graders versus 8 th graders.

The exponentiated coefficients reported in the specific indirect effects of arrest section (ab paths) are interpreted as percentage increases in delinquency following arrest via each mediator. For 7 th graders, arrest is associated with a $10 \%$ increase in delinquency via neutralizations and neutralizations account for 5 and $3 \%$ increases in delinquency for 8th and 9th graders, respectively. Involvement with delinquent peers

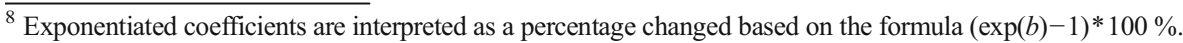


Table 2 Path model results

\begin{tabular}{|c|c|c|c|c|c|c|}
\hline & 7th grac & $(n=2764)$ & 8th grac & $(n=3046)$ & 9th grad & $(n=$ \\
\hline Direct effects of arrest on labelin & mechan & sms (a paths & & & & \\
\hline & $b$ & $\mathrm{SE}$ & $b$ & SE & $b$ & SE \\
\hline Lack of guilt ${ }^{\mathrm{b}}$ & $.39 * * *$ & .05 & $.28 * * *$ & .05 & $.18^{* *}$ & .06 \\
\hline Neutralizations $\mathrm{s}^{\mathrm{a}, \mathrm{b}}$ & $.45^{* * *}$ & .07 & $.21 * * *$ & .06 & $.18^{* *}$ & .07 \\
\hline Poor grades & $.30 * * *$ & .08 & $.30 * * *$ & .07 & .16 & .08 \\
\hline Weak school commitment ${ }^{\mathrm{a}, \mathrm{b}}$ & $.42 * * *$ & .06 & $.22 * * *$ & .06 & $.13^{*}$ & .06 \\
\hline Prosocial activity exclusion ${ }^{\mathrm{b}}$ & $.32 * * *$ & .09 & .13 & .09 & -.10 & .11 \\
\hline Prosocial peer exclusion ${ }^{\mathrm{a}, \mathrm{b}}$ & $.52^{* * *}$ & .07 & $.19^{* *}$ & .06 & $.25^{* *}$ & .08 \\
\hline Delinquent peers ${ }^{\mathrm{a}, \mathrm{b}}$ & $.85^{* * *}$ & .08 & $.52 * * *$ & .06 & $.41 * * *$ & .07 \\
\hline Negative peer commitment ${ }^{\mathrm{a}, \mathrm{b}}$ & $.72 * * *$ & .10 & $.26^{* *}$ & .08 & .15 & .09 \\
\hline
\end{tabular}

Direct effects of labeling mechanisms on delinquency ( $b$ paths)

\begin{tabular}{|c|c|c|c|c|c|c|c|c|c|}
\hline & $b$ & SE & $\exp (b)$ & $b$ & SE & $\exp (b)$ & $b$ & SE & $\exp (b)$ \\
\hline Lack of guilt ${ }^{\mathrm{a}}$ & .03 & .04 & 1.03 & $.22 * * *$ & .05 & 1.24 & $.15^{* *}$ & .05 & 1.16 \\
\hline Neutralizations & $.22 * * *$ & .04 & 1.25 & $.21 * * *$ & .04 & 1.24 & $.18 * * *$ & .04 & 1.19 \\
\hline Poor grades & .05 & .03 & 1.05 & $.08^{*}$ & .04 & 1.08 & $.12 * * *$ & .03 & 1.13 \\
\hline Weak school commitment & $.20 * * *$ & .04 & 1.22 & $.10 *$ & .04 & 1.10 & $.14 * *$ & .05 & 1.15 \\
\hline Prosocial activity exclusion & .00 & .02 & 1.00 & .00 & .02 & 1.00 & .00 & .02 & 1.00 \\
\hline Prosocial peer exclusion & .02 & .03 & 1.02 & .02 & .03 & 1.02 & .05 & .03 & 1.05 \\
\hline Delinquent peers & $.26^{* * *}$ & .06 & 1.29 & $.22 * * *$ & .06 & 1.24 & $.28 * * *$ & .06 & 1.33 \\
\hline Negative peer commitment ${ }^{\mathrm{a}}$ & $.13 * * *$ & .03 & 1.14 & .05 & .03 & 1.05 & .06 & .03 & 1.06 \\
\hline \multicolumn{10}{|c|}{ pecific indirect effects of arrest (ab paths) } \\
\hline & $b$ & SE & $\exp (b)$ & $b$ & SE & $\exp (b)$ & $b$ & SE & $\exp (b)$ \\
\hline Lack of guilt ${ }^{\mathrm{a}}$ & .01 & .02 & 1.01 & $.06^{* * *}$ & .02 & 1.06 & $.03 *$ & .01 & 1.03 \\
\hline Neutralizations ${ }^{\mathrm{b}}$ & $.10^{* * *}$ & .02 & 1.10 & $.04 * *$ & .02 & 1.05 & $.03 *$ & .01 & 1.03 \\
\hline Poor grades & .01 & .01 & 1.01 & .02 & .01 & 1.02 & .02 & .01 & 1.02 \\
\hline Weak school commitment ${ }^{\mathrm{a}, \mathrm{b}}$ & $.08 * * *$ & .02 & 1.09 & $.02 *$ & .01 & 1.02 & .02 & .01 & 1.02 \\
\hline Prosocial activity exclusion & .00 & .01 & 1.00 & .00 & .00 & 1.00 & .00 & .00 & 1.00 \\
\hline Prosocial peer exclusion & .01 & .02 & 1.01 & .00 & .01 & 1.00 & .01 & .01 & 1.01 \\
\hline Delinquent peers & $.22 * * *$ & .06 & 1.24 & $.11 * * *$ & .03 & 1.12 & $.12 * * *$ & .03 & 1.12 \\
\hline Negative peer commitment ${ }^{\mathrm{a}, \mathrm{b}}$ & $.09^{* * *}$ & .03 & 1.10 & .01 & .01 & 1.01 & .01 & .01 & 1.01 \\
\hline Total indirect ${ }^{\mathrm{a}, \mathrm{b}}$ & $.53 * * *$ & .07 & 1.70 & $.28^{* * *}$ & .04 & 1.32 & $.23^{* * *}$ & .05 & 1.26 \\
\hline \multicolumn{10}{|l|}{ ffects of arrest on delinquency } \\
\hline & $b$ & SE & $\exp (b)$ & $b$ & SE & $\exp (b)$ & $b$ & SE & $\exp (b)$ \\
\hline Direct (c' path) & $.31 *$ & .13 & 1.36 & $.39 * *$ & .11 & 1.47 & .21 & .13 & 1.23 \\
\hline Total (c path) ${ }^{\mathrm{b}}$ & $.84 * * *$ & .13 & 2.32 & $.67 * * *$ & .11 & 1.95 & $.44 * *$ & .13 & 1.55 \\
\hline
\end{tabular}

Coefficients are unstandardized. All differences are significant at $p<.05$

$S E$ standard error, $\exp (b)$ exponentiated coefficient

${ }^{*} p<.05,{ }^{* *} p<.01,{ }^{* * *} p<.001$

${ }^{a} 7$ th and 8 th grade coefficients are significantly different

${ }^{\mathrm{b}} 7$ th and 9 th grade coefficients are significantly different 
also significantly mediates the effect of arrest for the three grade cohorts. In addition to these significant mediators, weak school commitment explains a portion of the increase in delinquency following arrest for 7 th and 8th graders, while negative peer commitment accounts for a portion of the increased delinquency for 7 th graders only. Among the 8th and 9th grade cohorts, lack of guilt significantly mediates the relationship between arrest and delinquency. The results of Wald tests indicate that a number of these indirect effects are significantly different in magnitude. Specifically, the effect of arrest on delinquency via school commitment and commitment to negative peers is significantly stronger for 7 th graders compared with 8 th or 9 th grade youth. The indirect effect via neutralizations is also significantly greater for 7 th graders than for 9th graders. Alternatively, arrest is associated with a greater increase in delinquency via lack of guilt for 8 th graders than for 7 th graders. In total, the labeling mechanisms account for a $70 \%$ increase in delinquency for the 7 th grade cohort, but only 32 and $26 \%$ increases in delinquency for 8th and 9th graders, respectively. Difference tests indicate that the effect of arrest via all of the labeling mechanisms simultaneously is significantly stronger in magnitude for 7 th graders versus 8 th or 9 th graders.

The direct and total effects of arrest on delinquency are presented in the final set of results in Table 2. After accounting for increases in delinquency via the labeling mechanisms, the direct effect reveals that arrest is associated with a $36 \%$ increase in delinquency among 7 th graders, a $47 \%$ increase in delinquency among 8th graders, and a non-significant increase within the 9 th grade cohort. Although Wald tests indicate that differences across groups are not statistically significant. The total effects, however, show that when both direct and indirect effects via mediators are combined, arrest is associated with the largest increase in delinquency among 7 th graders - at $132 \%$ followed by 8th graders at $95 \%$ and 9 th graders at $55 \%$. Wald tests reveal that the difference in the total effect between 7 th and 9 th graders is significant.

\section{Discussion}

A number of precocious transitions and off-timed events are associated with increased delinquency during adolescence, including early puberty and steady employment [15, 70]. The current study indicates that an additional event, arrest, has differential effects for youth at different stages in the socially structured developmental sequence. Informed by labeling theory and its extensions, this study adds to the prior literature by providing an in-depth examination of the multiple pathways that lead to delinquency. Although the results from this study indicate that arrest is detrimental whether it occurs in 7 th, 8th, or 9th grade, the greatest differences in the effects of arrest are between 7 th and 9 th graders, with the youngest cohort being most negatively affected by arrest. Arrest influences each of the intermediate outcomes among 7th graders, affecting youth's deviant attitudes, both prosocial and antisocial peer associations, academic achievement and commitment, involvement in prosocial activities, and delinquent behavior. Moreover, as these consequences unfold over time, we see that arrest indirectly affects delinquent behavior primarily through agreement with neutralization statements, commitment to school, and involvement with and commitment to delinquent peers. The effects of arrest operate somewhat differently for 8th and 9th 
graders: arrest is linked to increased delinquency via delinquent peers and agreement with neutralization statements, but lack of guilt also accounts for some of the increase in delinquency for 8th and 9th graders only. These findings are largely consistent with prior research that indicates that the effects of official and unofficial labels are most detrimental for younger adolescents (see, for example, $[16,33,75]$ ), but some of the differences across age groups are not in line with the hypotheses outlined in this study.

Consistent with hypothesis 1 , arrest has the strongest effect on 7 th graders when it comes to deviant attitudes and potentially, deviant identity. This finding may be due, in part, to the fact that the identities and attitudes of younger adolescents are more malleable than their older counterparts $[17,20]$, but might also reflect societal norms related to delinquent behavior. When 7 th graders are arrested, it is more likely that parents and teachers view their behavior as troublesome and problematic because arrest is a relatively rare event for these youth. As younger youth tend to more heavily rely on the expectations and values of adults, they are more likely than their older peers to view their own behavior as problematic and adopt attitudes and beliefs that are in line with those views. Indirect effects reveal that while agreement with neutralization statements explains some increase in delinquency among 7th graders, lack of guilt does not. Moreover, the indirect effect via neutralizations, although significant, is small in magnitude. This finding indicates that, at most, the effects of arrest are largely limited to the direct effect on these attitudes and do not translate into dramatically higher levels of delinquency for these youth. It is important to note that although changes in deviant identity should be measurable, in part, by attitudes that are increasingly supportive of deviance (see [1]), more direct measures of self-perceptions or self-esteem are needed to capture deviant identity.

Contrary to expectations, the effect of arrest on delinquency via lack of guilt is significantly stronger for 8th grade youth than for 7 th graders. This effect is largely driven by differences in the effect of lack of guilt on delinquency rather than by age-graded differences in the effects of arrest and, thus, cannot be explained by differences in the labeling process. Moreover, if age-graded patterns explain the stronger relationship between lack of guilt and delinquency among older youth, a similar significant difference should emerge when comparing 7th and 9th graders. Because a difference between 7 th and 9th graders did not emerge, it is unclear whether the difference between 7 th and 8 th graders is the result of the changing relationship between attitudes/emotions and delinquency or an artifact of the sample.

Turning to hypothesis 2, this study provides support for the idea that arrest is associated with greater attenuation of prosocial bonds, both in terms of school commitment and involvement with prosocial peers and activities, among the youngest youth in this sample. This finding is consistent with Moffitt's [57] work: younger youth who are delinquent or experience arrest are viewed as "problem youth" and are more likely to be excluded by their prosocial peers, but older youth who have similar experiences are viewed as "normal." However, neither prosocial activity nor prosocial peer exclusion accounts for later delinquency. One explanation for this finding is that although youth are not involved with prosocial peers and activities, this does not mean that they are more involved in delinquency. Moreover, the term "exclusion" implies that these youth wanted to be part of prosocial groups and were not allowed, yet that is not the case in this study. Rather, "exclusion" is consistent the idea that - either by 
choice or not - individuals who have been arrested do not participate in conventional activities or groups. Future work should consider whether there are differences in the effects of arrest in terms of choosing to participate in prosocial groups or activities versus being explicitly excluded from them.

Consistent with labeling theory and age-graded expectations, arrest is associated with weaker commitment to school, which partially mediates the relationship between arrest and delinquency among 7th graders. This finding is consistent with De Li's [16] research and likely reflects a difference in how younger youth view the effect of their arrest on chances for academic success, causing them to become less committed to school as they pull away from this formal social institution.

Concerning hypothesis 3 , the results of this study do not support the idea that younger youth have limited access to deviant peers and are therefore less likely than their older counterparts to become involved with deviant groups as a result of arrest. Instead, findings indicate that arrest is associated with significantly more involvement with and commitment to delinquent peers for 7 th graders versus their 8 th and 9th grade counterparts. After taking into account the above finding - that younger youth are less likely to be involved with prosocial groups and peers following arrest-younger youth potentially have fewer opportunities for prosocial groups and thus deviant groups are the most likely type of group, possibly even the only option, for younger youth to engage with following arrest. As delinquency becomes normative, older youth might find that their friends participate in both prosocial and delinquent activities, and these youth likely have access to a broader range of peer groups that are accepting of delinquent behavior. In addition to finding differences in the direct effect of arrest on deviant peer groups, the findings from this study also show that commitment to negative peers - or the choice to go along with deviant peers even when they are getting into trouble - significantly mediates the relationship between arrest and delinquency for 7 th graders but not for 8 th or 9 th graders. This finding is consistent with the notion that younger youth are more susceptible to peer pressure (see [10]) and thus are more likely to participate in delinquency as a result.

One of the strengths of the current study is that it assesses the shorter-term consequences of arrest during adolescence, allowing for comparison of the effects of arrest at a salient transition point: the move from middle to high school. During this time, youth are thrust into an environment with new teachers, peers, and social hierarchies, which could compound the detrimental effects of arrest as youth attempt to navigate this rocky transition. But the transition to high school offers new opportunities and the chance to begin the year with a clean slate, allowing arrested youth to escape their previous labels. The findings regarding indirect, direct, and total effects of arrest on delinquency indicate that the consequences of arrest across multiple domains decline as youth age, but this decline does not appear to be explained by the transition to high school. A substantial and significant direct effect of arrest on delinquency remains for youth who experienced arrest in 8th grade. Moreover, in total, arrest exerts a significant effect on delinquency for all three grade cohorts. However, because the labeling mechanisms and arrest are measured during the same grade level, it cannot be ruled out that the transition to high school plays some part in differences by grade level. To revisit this question, additional research must examine whether indirect effects via labeling mechanisms remain when arrest is measured in 8 th grade and mediators in 9th grade. 


\section{Conclusions}

While the age range of this study is limited to a relatively short window, the findings indicate that as delinquency becomes more normative and youth approach the peak of the age-crime curve, the effects of arrest become less detrimental. Specifically, the findings indicate that the consequences of arrest are widest-ranging and most substantial in magnitude among younger youth and these effects taper off, but do not disappear, as youth age. This study also finds that the factors that account for increased delinquency following arrest vary with age - with school commitment, agreement with neutralization statements, and commitment to deviant peers becoming less salient over time. To counteract these negative effects, particularly for younger youth, it is necessary to focus on the primary mechanisms that account for delinquency. The strong effect of arrest on the deviant peer group domain suggests that youth who experience arrest at younger ages either have few non-delinquent peer group options or prefer delinquent groups. Limiting younger youth's contact with delinquent youth and promoting involvement with prosocial peers and groups should help to decrease the negative effect of arrest as it relates to involvement with and commitment to delinquent peers. Parents and other adults should attempt to prevent negative changes in youth's attitudes by building positive identities early on and helping to counteract the negative consequences of arrest by providing support after their experiences with the justice system (see, for example, [37]). Ensuring that the behavior, rather than the individual, is punished or labeled should also help reduce the likelihood that youth will adopt deviant attitudes and identities [11], especially among younger youth whose attitudes and beliefs are most malleable.

Early intervention is considered a promising avenue for addressing youth's behavioral problems (e.g., $[25,80]$ ), but the results from this study indicate that younger adolescents fare worse than their older counterparts in terms of negative consequences related to arrest, calling into question the types of early intervention that should be utilized. To be sure, this is not to say that early intervention is not warranted in some cases, but it is necessary to understand the potential consequences that all types of intervention have and most notably, interventions that rely on official actors of the justice system. Importantly, this study does not assess the effects of first experiences with the police, but given the average age of the youngest cohort in this study, it is relatively unlikely that these youth experienced police contact prior to the time point at which arrest was measured. ${ }^{9}$ Still, future research should consider how age matters in terms of youth's first arrests, as these experiences may have the most detrimental impact (for more information on the effects of first arrest, see [47]).

Labeling theory has been identified as one of the only truly developmental theories of crime [51,64] and while research increasingly examines the age-graded consequences of justice system involvement, this work largely focuses on late adolescence and early adulthood (for review, see [4, 35]). Additional research is necessary to understand how justice system intervention that occurs in middle school - and even earlier in life - unfolds to impact youth throughout adolescence and adulthood. The need for longitudinal research extending beyond 5 or even 10 years is necessary for

\footnotetext{
${ }^{9}$ Brame and colleagues [12] estimate that approximately $2 \%$ of youth are arrested by age 13 , just under $4 \%$ are arrested by age 14 , and nearly $7 \%$ of youth report experiencing arrest before turning 15 .
} 
developmental criminologists to better understand the impact of justice system involvement on the lives of youth. But while a long view of development is necessary, it is important that researchers continue to explore development in context (see $[67,71]$ ), which may be most pronounced within shorter windows of time surrounding other salient life events.

Acknowledgments This research was made possible, in part, by the support and participation of seven school districts, including the School District of Philadelphia. This project was supported by Award No. 2006JV-FX-0011 awarded by the National Institute of Justice, Office of Justice Programs, US Department of Justice. The opinions, findings, and conclusions or recommendations expressed in this manuscript are those of the author and do not necessarily reflect the views of the Department of Justice or of the seven participating school districts. The author would like to thank Finn-Aage Esbensen and Lee Slocum for their suggestions and comments.

\section{References}

1. Ageton, S. S., \& Elliott, D. S. (1974). The effects of legal processing on delinquent orientations. Social Problems, 22(1), 87-100.

2. Allison, P. (2012). Handling missing data by maximum likelihood. SAS Global Forum.

3. Barber, B. K., \& Olsen, J. A. (2004). Assessing the transitions to middle and high school. Journal of Adolescent Research, 19(1), 3-30.

4. Barrick, K. (2014). A review of prior tests of labeling theory. In D. P. Farrington \& J. Murray (Eds.), Labeling theory: empirical tests (pp. 89-112). New Brunswick, NJ: Transaction Publishers.

5. Becker, H. (1991). Outsiders. New York: The Free Press. 1963.

6. Benner, A. D. (2011). The transition to high school: current knowledge, future directions. Educational Psychology Review, 23(3), 299-328.

7. Bernburg, J. G. (2009). Labeling theory. In M. D. Krohn, A. J. Lizotte, \& G. P. Hall (Eds.), Handbook on crime and deviance (pp. 187-207). New York: Springer.

8. Bernburg, J. G., \& Krohn, M. D. (2003). Labeling, life chances, and adult crime: the direct and indirect effects of official intervention in adolescence on crime in early adulthood. Criminology, 41(4), 12871318.

9. Bernburg, J. G., Krohn, M. D., \& Rivera, C. J. (2006). Official labeling, criminal embeddedness, and subsequent delinquency: a longitudinal test of labeling theory. Journal of Research in Crime and Delinquency, 43(1), 67-88.

10. Blakemore, S.-J., \& Mills, K. L. (2014). Is adolescence a sensitive period for sociocultural processing? Annual Review of Psychology, 65, 187-207.

11. Braithwaite, J. (1989). Crime, shame and reintegration. Cambridge, UK: Cambridge University Press.

12. Brame, R., Turner, M. G., Paternoster, R., \& Bushway, S. D. (2012). Cumulative prevalence of arrest from ages 8 to 23 in a national sample. Pediatrics, 129(1), 21-7.

13. Brayne, S. (2014). Surveillance and system avoidance: criminal justice contact and institutional attachment. American Sociological Review, 79(3), 367-391.

14. Buchanan, C. M., \& Holmbeck, G. N. (1998). Measuring beliefs about adolescent personality and behavior. Journal of Youth and Adolescence, 27(5), 607-627.

15. Caspi, A., \& Moffitt, T. E. (1991). Individual differences are accentuated during periods of social change: the sample case of girls at puberty. Journal of Personality and Social Psychology, 61(1), 157-168.

16. De Li, S. (1999). Legal sanctions and youths' status achievement: a longitudinal study. Justice Quarterly, 16(2), 377-401.

17. Demo, D. H. (1992). The self-concept over time: research issues and directions. Annual Review of Sociology, 18, 303-326.

18. Eccles, J. S., Midgley, C., Wigfield, A., Buchanan, C. M., Reuman, D., Flanagan, C., \& MacIver, D. (1993). Development during adolescence: the impact of stage-environment fit on young adolescents' experiences in schools and in families. American Psychologist, 48(2), 90-101. 
19. Elliott, D. S., \& Menard, S. (1996). Delinquent friends and delinquent behavior: temporal and developmental patterns. In J. D. Hawkins (Ed.), Delinquency and crime (pp. 28-67). Cambridge, England: Cambridge University Press.

20. Erikson, E. H. (1968). Identity: youth and crisis. New York: W. W. Norton and Company.

21. Esbensen, F.-A., \& Huizinga, D. (1993). Gangs, drugs, and delinquency in a survey of urban youth. Criminology, 31(4), 565-589.

22. Esbensen, F.-A., Melde, C., Taylor, T. J., \& Peterson, D. (2008). Active parental consent in school-based research: how much is enough and how do we get it? Evaluation Review, 32(4), 335-362.

23. Esbensen, F.-A., Osgood, D. W., Peterson, D., Taylor, T. J., \& Carson, D. C. (2013). Short- and long-term outcome results from a multisite evaluation of the G.R.E.A.T. program. Criminology and Public Policy, 12(3), 375-411.

24. Esbensen, F.-A., Peterson, D., Taylor, T. J., \& Osgood, D. W. (2012). Results from a multi-site evaluation of the G.R.E.A.T. program. Justice Quarterly, 29(1), 125-151.

25. Farrington, D. P. (2012). Should the juvenile justice system be involved in early intervention? Criminology and Public Policy, 11(2), 265-273.

26. Farrington, D. P., Loeber, R., Elliott, D. S., Hawkins, J. D., Kandel, D. B., Klein, M. W., McCord, J., Rowe, D. C., \& Tremblay, R. E. (1990). Advancing knowledge about the onset of delinquency and crime. In B. B. Lahey \& A. E. Kazdin (Eds.), Advances in clinical child psychology (Vol. 13, pp. 283-314). New York: Plenum Press.

27. Feld, B. C. (1999). Bad kids: race and the transformation of the juvenile court. New York: Oxford University Press.

28. Gilman, A. B., Hill, K. G., \& Hawkins, J. D. (2015). When is a youth's debt to society paid? Examining the long-term consequences of juvenile incarceration for adult functioning. Journal of Developmental and Life Course Criminology, 1(1), 33-47.

29. Fuligni, A. J., Eccles, J. S., Barber, B. L., \& Clements, P. (2001). Early adolescent peer orientation and adjustment during high school. Developmental Psychology, 37(1), 28-36.

30. Goffman, E. (1963). Stigma: notes on the management of a spoiled identity. Englewood Cliffs, NJ: Prentice Hall.

31. Gordon, C. (1976). Development of evaluated role identities. Annual Review of Sociology, 2, 405-433.

32. Hayes, A. F. (2013). Introduction to mediation, moderation, and conditional process analysis. New York: The Guilford Press.

33. Heimer, K., \& Matsueda, R. L. (1994). Role-taking, role commitment, and delinquency: a theory of differential social control. American Sociological Review, 59(3), 365-390.

34. Hoffman, J. P., \& Cerbone, F. G. (1999). Stressful life events and delinquency escalation in early adolescence. Criminology, 37(2), 343-374.

35. Huizinga, D., \& Henry, K. L. (2008). The effect of arrest and justice system sanctions on subsequent behavior: findings from longitudinal and other studies. In A. M. Liberman (Ed.), The long view of crime: $a$ synthesis of longitudinal research (pp. 220-254). New York: Springer.

36. Isakson, K., \& Jarvis, P. (1999). The adjustment of adolescents during the transition into high school: a short-term longitudinal study. Journal of Youth and Adolescence, 28(1), 1-26.

37. Jackson, D. B., \& Hay, C. (2013). The conditional impact of official labeling on subsequent delinquency: considering the attenuating role of family attachment. Journal of Research in Crime and Delinquency, $50(2), 300-322$.

38. Johnson, L. M., Simons, R. L., \& Conger, R. D. (2004). Criminal justice system involvement and continuity of youth crime: a longitudinal analysis. Youth and Society, 36(1), 3-29.

39. Jones-Brown, D., Gill, J., \& Trone, J. (2010). Stop, question, and frisk policing practices in New York City: a primer. New York: John Jay College of Criminal Justice.

40. Kaplan, H. B., \& Johnson, R. J. (1991). Negative social sanctions and juvenile delinquency: effects of labeling in a model of deviant behavior. Social Science Quarterly, 72(1), 98-122.

41. Kinney, D. A. (1993). From nerds to normals: the recovery of identity among adolescents from middle school to high school. Sociology of Education, 66(1), 21-40.

42. Kirk, D. S., \& Sampson, R. J. (2013). Juvenile arrest and collateral educational damage in the transition to adulthood. Sociology of Education, 86(1), 36-62.

43. Lanctôt, N., Cernkovich, S. A., \& Giordano, P. C. (2007). Delinquent behavior, official delinquency, and gender: consequences for adulthood functioning and well-being. Criminology, 45(1), 131-157.

44. Larson, R., \& Ham, M. (1993). Stress and 'storm and stress' in early adolescence: the relationship of negative events with dysphoric affect. Developmental Psychology, 29(1), 130-140.

45. Lemert, E. M. (1951). Social pathology. New York: McGraw-Hill. 
46. Lemert, E. M. (1972). Human deviance, social problems, and social control. Englewood Cliffs, NJ: Prentice Hall. 1967.

47. Liberman, A. M., Kirk, D. S., \& Kim, K. (2014). Labeling effects of first juvenile arrests: secondary deviance and secondary sanctioning. Criminology, 52(3), 345-370.

48. Link, B. G. (1982). Mental patient status, work, and income: an examination of the effects of a psychiatric label. American Sociological Review, 47(2), 202-215.

49. Link, B. G., Cullen, F. T., Struening, E., Shrout, P. E., \& Dohrenwend, B. P. (1989). A modified labeling theory approach to mental disorders: an empirical assessment. American Sociological Review, 54(3), 400423.

50. Loeber, R. (1982). The stability of antisocial and delinquent child behavior: a review. Child Development, 53(6), 1431-1446.

51. Loeber, R., \& LeBlanc, M. (1990). Toward a developmental criminology. In M. Tonry \& N. Morris (Eds.), Crime and justice (Vol. 12, pp. 375-437). Chicago: University of Chicago Press.

52. Lofland, J. (2002). Deviance and identity. Englewood Cliffs, NJ: Prentice-Hall. 1969.

53. Lopes, G., Krohn, M. D., Lizotte, A. J., Schmidt, N. M., Vásquez, B. E., \& Bernburg, J. G. (2012). Labeling and cumulative disadvantage: the impact of formal police intervention on life chances and crime during emerging adulthood. Crime and Delinquency, 58(3), 456-488.

54. Massoglia, M., \& Uggen, C. (2010). Settling down and aging out: toward an interactionist theory of desistance and the transition to adulthood. American Journal of Sociology, 116(2), 543-582.

55. Matsueda, R. L. (1992). Reflected appraisals, parental labeling, and delinquency: specifying a symbolic interactionist theory. American Journal of Sociology, 97(6), 1577-1611.

56. Matsueda, R. L., \& Heimer, K. (2009). A symbolic interactionist theory of role-transitions, role-commitments, and delinquency. In T. P. Thornberry (Ed.), Developmental theories of crime and delinquency ( $p p$. 163-213). New Brunswick, NJ: Transaction Publishers. 1997.

57. Moffitt, T. E. (1993). Adolescence-limited and life-course-persistent antisocial behavior: a developmental taxonomy. Psychological Review, 100(4), 674-701.

58. O’Brien, S. F., \& Bierman, K. L. (1988). Conceptions and perceived influence of peer groups: interviews with preadolescents and adolescents. Child Development, 59(5), 1360-1365.

59. O’Hara, R. B., \& Kotze, D. J. (2010). Do not log-transform count data. Methods in Ecology and Evolution, 1(2), 118-122.

60. Paternoster, R., \& Iovanni, L. (1989). The labeling perspective and delinquency: an elaboration of the theory and an assessment of the evidence. Justice Quarterly, 6(3), 360-394.

61. Petteruti, A. (2011). Education under arrest: the case against police in schools. Washington, DC: Justice Policy Institute.

62. Preacher, K. J., \& Hayes, A. F. (2008). Asymptotic and resampling strategies for assessing and comparing indirect effects in multiple mediator models. Behavior Research Methods, 40(3), 879-891.

63. Sampson, R. J., \& Laub, J. H. (1993). Crime in the making: pathways and turning points through life. Cambridge, MA: Harvard University Press.

64. Sampson, R. J., \& Laub, J. H. (1997). A life-course theory of cumulative disadvantage and the stability of delinquency. In T. P. Thornberry (Ed.), Developmental theories of crime and delinquency (pp. 133-61). New Brunswick, NJ: Transaction Publishers.

65. Seidman, E., Aber, J. L., Allen, L., \& French, S. E. (1996). The impact of the transition to high school on the self-system and perceived social context of poor urban youth. American Journal of Community Psychology, 24(4), 489-515.

66. Simmons, R. G., Burgeson, R., Carlton-Ford, S., \& Blyth, D. A. (1987). The impact of cumulative change in early adolescence. Child Development, 58(5), 1220-1234.

67. Smetana, J. G., Campione-Barr, N., \& Metzger, A. (2006). Adolescent development in interpersonal and society contexts. Annual Review of Psychology, 57, 255-284.

68. Smith, D. A., \& Paternoster, R. (1990). Formal processing and future delinquency: deviance amplification as selection artifact. Law and Society Review, 24(5), 1109-1131.

69. StataCorp. (2013). Stata Statistical Software: Release 13. College Station, TX: StataCorp LP.

70. Steinberg, L., Fegley, S., \& Dornbusch, S. M. (1993). Negative impact of part-time work on adolescent adjustment: evidence from a longitudinal study. Developmental Psychology, 29(2), 171-180.

71. Steinberg, L., \& Morris, A. S. (2001). Adolescent development. Annual Review of Psychology, 52, 83110 .

72. Sweeten, G. (2006). Who will graduate? Disruption of high school education by arrest and court involvement. Justice Quarterly, 23(4), 462-480.

73. Thomas, K. J., \& McGloin, J. M. (2013). A dual-systems approach for understanding differential susceptibility to processes of peer influence. Criminology, 51(2), 435-474. 
74. Triplett, R. A. (1993). The conflict perspective, symbolic interactionism, and the status characteristic hypothesis. Justice Quarterly, 10(4), 541-558.

75. Triplett, R. A., \& Jarjoura, G. R. (1994). Theoretical and empirical specification of a model of informal labeling. Journal of Quantitative Criminology, 10(3), 241-276.

76. Wiesner, M., Kim, H. K., \& Capaldi, D. M. (2010). History of juvenile arrests and vocational career outcomes for at-risk young men. Journal of Research in Crime and Delinquency, 47(1), 91-117.

77. Wiley, S. A., \& Esbensen, F.-A. (2013). The effect of police contact: does official intervention result in deviance amplification? Crime and Delinquency. doi:10.1177/0011128713492496.

78. Wiley, S. A., Slocum, L. A., \& Esbensen, F.-A. (2013). The unintended consequences of being stopped or arrested: an exploration of the labeling mechanisms through which police contact leads to subsequent delinquency. Criminology, 51(4), 927-966.

79. Wooldridge, J. M. (2002). Econometric analysis of cross-section and panel data. Boston, MA: MIT Press.

80. Wright, J. P., McMahon, P. M., Daly, C., \& Haney, J. P. (2012). Getting the law involved: a quasiexperiment in early intervention involving collaboration between schools and the district attorney's office. Criminology and Public Policy, 11(2), 227-249.

81. Zhang, L. (1997). Informal reactions and delinquency. Criminal Justice and Behavior, 24(1), 129-150. 